\title{
Hugues de Varine e os museus comunitários no Brasil
}

\author{
Roberto Fernandes dos Santos Junior \\ Clovis Carvalho Britto
}

\begin{abstract}
Resumo
Entrevista realizada com Hugues de Varine em 22 de janeiro de 2017 visando explicitar aspectos de sua trajetória, pensamento e relação com os museus e a Museologia Comunitária no Brasil. Ao privilegiar essa temática, a entrevista se torna fonte significativa para a visualização de um mapeamento de iniciativas comunitárias que o consultor francês integrou no campo dos museus, da Museologia e do Patrimônio no Brasil.
\end{abstract}

\section{Palavras-chave}

Hugues de Varine; Museus Comunitários; Museologia no Brasil.

\begin{abstract}
Interview with Hugues de Varine on January 22, 2017 aimed at clarifying aspects of his trajectory, thought and relation with museums and Community Museology in Brazil. By focusing on this theme, the interview becomes a significant source for the visualization of a mapping of community initiatives that the French consultant has integrated in the field of museums, Museology and Patrimony in Brazil.
\end{abstract}

\section{Keywords}

Hugues de Varine; Community Museums; Museology in Brazil.

Hugues de Varine é um dos principais nomes da Museologia. Nascido em 1935, na França, é graduado e pós-graduado em História. Foi membro do Conselho Internacional de Museus - ICOM, assumindo sua Vice-Diretoria e, posteriormente, a Direção Geral. Sua produção teórica e suas contribuições na implantação de museus comunitários em diversos países são fundamentais para repensar as configurações dos museus, dos patrimõnios e da Museologia. Integrou o Ecomuseu de Creusot-Montceau, na França, projeto ecomuseológico pioneiro. É membro do Movimento Internacional para uma Nova Museologia - MINOM e, atualmente, realiza atividades como consultor internacional em patrimônio e desenvolvimento comunitário.

A trajetória de Varine resume momentos significativos da memória do pensamento museológico contemporâneo. No caso brasileiro sua atuação merece ser revisitada, demonstrando como imprimiu transformações nos museus e na Museologia ao longo do século XX e impacta o campo da Museologia e do Patrimônio em discussões teóricas e em projetos de intervenção. $O$ seu contato com Paulo Freire, a sua aproximação com museólogos e profissionais do campo do patrimônio em diversos estados no Brasil, suas ações de consultoria na criação de museus comunitários, na organização de encontros e espaços de reflexão sobre diferentes processos de Museologia Comunitária, podem ser visualizadas em publicações de artigos, livros e entrevistas que impactaram e impactam um conjunto heterogêno de iniciativas do que em Portugal é entendido como Sociomuseologia e no Brasil se designa de Museologia Social. 
No Brasil são constantemente citados dois livros de sua autoria: $O$ tempo social , lançado em 1987, traduzido por Fernanda Camargo-Moro e Lourdes Rego Novaes, e Raízes do futuro: o patrimônio a serviço do desenvolvimento local , publicado em 2012, com tradução de Maria de Lourdes Parreiras Horta. Ainda em 1979, seu pensamento foi amplamente difundido por meio da entrevista publicada no livro Os museus no mundo, integrante da coleção Grandes Temas da Biblioteca Salvat e que, segundo Mario Chagas e Inês Gouveia, se tornou uma "referência fundamental e obrigatória, num documento de grande importância para a formação de uma nova geração de museólogos, educadores, historiadores, antropólogos e outros profissionais interessados no mundo dos museus".

Algumas pistas da relação de Hugues de Varine com a Museologia e os museus comunitários brasileiros podem ser evidenciadas, por exemplo, nos textos de Odalice Priosti , Maria de Lourdes Parreiras Horta e Roberto Fernandos dos Santos Junior ; e na entrevista que concedeu para o museólogo Mario Chagas .

A entrevista agora publicada na Revista Museologia e Interdisciplinaridade pretende integrar esse conjunto e foi realizada por escrito em 22 de janeiro de 2017 pelo museólogo Roberto Fernandes dos Santos Junior.As respostas em francês foram traduzidas pelo pesquisador Clovis Carvalho Britto, que também supervisionou a elaboração das questões.

As respostas de Varine estimularam Roberto Fernandes a elaborar a dissertação Por uma "Museologia da Libertação": impactos do pensamento de Hugues de Varine no campo museal brasileiro, a ser defendida no início de 2019 no Mestrado em Museologia da Universidade Federal da Bahia. A entrevista ocorreu quando Hugues de Varine escrevia L'écomusée singulier et pluriel: un témoignage sur cinquante ans de muséologie communautaire dans le monde, livro em que o autor dedicou um dos capítulos para explicitar aspectos de sua relação com a Museologia, o Patrimônio e a Educação no Brasil.

Fica o estímulo para que novos desdobramentos ocorram em torno do pensamento-ação de Varine, personagem que, assim como a sua concepção de ecomuseu, é singular por ser plural.

No que tange aos termos e conceitos da Nova Museologia. Qual a diferença entre Ecomuseologia e Sociomuseologia?

H.V. - A Nova Museologia é um movimento de contestação da Museologia tradicional e de experimentação de novas formas de museus que valorizem o lugar dos museus na sociedade e novos modos de gestão de coleções. Ela é o fruto de transformações mais ou menos espontâneas que ocorreram nos anos 70 do século passado (Conferência do Conselho Internacional de Museus de Grenoble, Mesa Redonda de Santiago, primeiros museus de territórios ou ecomuseus etc.). Muito tem sido falado sobre a Nova Museologia, mas ela não tem sido teorizada, tornando-se essencialmente uma prática e um ideal. Ela pode ser aplicada tanto para a transformação interna de museus tradicionais, quanto para a criação de novos museus. A Ecomuseologia é uma palavra, também não codificada, que abrange uma série de práticas de gestão do patrimônio por uma comunidade em um território. Essas práticas são conhecidas por diversos nomes: ecomuseus propriamente ditos, museus comunitários, museus locais. Elas assumem formas mais ou menos experimentais, inventando modos de ação e educação patrimonial relacionados aos territórios culturais, sociais, ambientais e econômicos. Ela 
não é respaldada em modelos, até porque não existem dois museus comunitários ou ecomuseus semelhantes: cada projeto, cada realização é única, porque cada comunidade, cada patrimônio e território são únicos. A Sociomuseologia é uma disciplina acadêmica, de origem luso-brasileira, que tenta definir cientificamente os fenômenos e os conceitos da Nova Museologia e da Ecomuseologia. Ela analisa as experiências visando observar as características comuns.

RFS]: O que viria a ser a "Museologia da Libertação" em aspectos teóricos e práticos?

H.V.: Em I97I, quando eu estava preparando a Mesa Redonda de Santiago, eu integrava como militante e cidadão, uma ONG chamada Instituto Ecumênico para o Desenvolvimento dos Povos - INODEP, cujo presidente foi Paulo Freire, então no exílio no Conselho Ecumêcnico de Igrejas, em Genebra. Eu perguntei a Paulo se ele aceitava ser o principal orador em Santiago, em 1972, e ele aceitou imediatamente trabalhar para adaptar as suas ideias sobre a educação libertária, a conscientiação etc. para os museus. Mas o governo brasileiro se recusou a deixá-lo ir para Santiago em uma missão da UNESCO.A partir desse momento, enquanto eu considerava Paulo Freire como meu mestre, comecei a refletir sobre um museu inspirado em suas ideias. Mais tarde, na década de 90 , quando comecei a ir regularmente ao Brasil, comecei a discutir as propostas de Paulo Freire com os colegas brasileiros. Eu também revi Paulo em São Paulo, em 1992. Depois, Odalice Priosti, quando ela fez seu doutorado na Universidade Federal do Estado do Rio de Janeiro, dedicou um capítulo inteiro de sua tese sobre a "Museologia da Libertação". Atualmente, o trabalho de Nadia Helena Almeida no Ecomuseu de Maranguape (CE) vai na mesma direção, com o conceito de Cidade Educadora e rede de internet. (Ver https://www.facebook.com/ aredejuntos/?ref=ts\&fref=ts e também http://cidadeseducadoras.org.br/metodologias/como-criar-um-museu-comunitario/ Eu creio que podemos dizer que, no Brasil particularmente, a concepção de museu comunitário e seu papel no desenvolvimento corresponde bem às ideias de Paulo Freire. Da mesma forma, a crítica da "educação bancária" pode facilmente ser aplicada a uma Museologia que promove o património "sem terra" desconectado da sociedade e da cultura vibrante. Mas se muito se fala sobre o diálogo de Paulo Freire e os museus brasileiros, à exceção de Odalice, creio que não houveram pesquisas ou publicações que enfocaram claramente uma "Museologia da Libertação".

RFSJ: Existem especificidades entre os ecomuseus latino-americanos e brasileiros?

H.V.: Não podemos dizer que há ecomuseus brasileiros ou latino-americanos. Existem na América Latina, e no Brasil, um grande número de museus comunitários, alguns dos quais levam o nome de ecomuseu, porque seus fundadores assim os designaram. Em termos brasileiros, os ecomuseus, museus de favelas, os museus indigenas, muitos Pontos de Memória, alguns terreiros e certas comunidades afrobrasileiras são museus comunitários. Muitas vezes o termo ecomuseu é escolhido para se distinguir do museu tradicional e destacar claramente sua relação com o território, a comunidade, a globalização do património vivo (natural e cultural, material e imaterial) etc. No México, existe uma grande quantidade de "Museus comunitários", mas poucos ecomuseus. A União dos Museus Comunitários da América os reconhece, eu creio, como ecomuseus, mas seus membros os denominam frequentemente de “Museus Comunitários”.Ver http:// 
www.museoscomunitarios.org. O único país onde os ecomuseus possuem um "rótulo" oficial é a Itália, onde as doze regiões adotaram "leis de ecomuseus" e estabeleceram critérios para a aprovação de tais ecomuseus, métodos de avaliação, redes regionais etc. $\mathrm{Na}$ China, os poucos ecomuseus se tornaram modelos para as "novas cidades". O mesmo ocorreu na Coréia. É por isso que o Fórum organizado em Milão em julho passado para os ecomuseus italianos abarcou "os ecomuseus e museus comunitários”.

RFSJ: Quando foi iniciado o seu trabalho de consultor em desenvolvimento? H.V.: Eu comecei a trabalhar em 1975, em uma agência de desenvolvimento público em um pequeno distrito ao norte de Paris. Em seguida, em 1985, trabaIhei para o desenvolvimento das zonas de habitação social na França e, em 1990, criei a minha empresa de consultoria em desenvolvimento local e comunitário (ASDIC) com a qual eu trabalhei na França e no estrangeiro (especialmente em Portugal e no Brasil). Cuidei em especial dos auxílios para a criação de empresas e empregos, inclusão social e projetos de desenvolvimento económico, cultural e social. Eu possuia uma equipe de cinco a sete pessoas e a sede era na minha cidade, na Borgonha. Em seguida, em 2000, eu continuei free lance e trabalhei principalmente em missões sobre o patrimônios e os ecomuseus, no Brasil e na Itália. Eu finalizei essa atividade profissional em 2013 e, desde esse momento, estou me dedicando ao ensino e ao acompanhamento de projetos, voluntários e gratuitos, especialmente na Itália.

RFSJ: Como se deu o seu envolvimento com o Brasil?

H. V.: Tudo começou em 1987, quando Fernanda Camargo Moro, que eu tinha conhecido quando eu dirigia o Conselho Internacional de Museus, traduziu e publicou em português meu livro $O$ tempo social (Editora Eça - em francês L'initiative Communautaire). Depois eu participei, em 1992 na primeira reunião internacional de ecomuseus no Rio de Janeiro, também organizado por Fernanda. Depois fui diversas vezes em Itaipu, Rio Grande do Sul, e Petrópolis (com Maria de Lourdes Parreiras Horta, que dirigia a equipe do Museu Imperial). Em 200 I e 2004, participei ativamente no segundo e terceiro Encontro Internacional de Ecomuseus e Museus Comunitários (II e III EIEMC) no Ecomuseu de Santa Cruz. Eu creio que duas razões expliquem meu envolvimento com o Brasil: eu poderia falar sobre o relacionamento dos museus com o desenvolvimento local, graças ao meu passado no Conselho Internacional de Museus e a minha profissão de agente de desenvolvimento; e também eu poderia falar um pouco de português, que eu aprendi em quase três anos em Portugal (1982-1984) como diretor do Instituto Franco-Português em Lisboa. Eu poderia, assim, acompanhar projetos de campo, com um olhar muito diferente, não como museólogo, mas associado a uma experiência de museus com um outro desenvolvimento dos territórios. Porque eu nunca quis dar conselhos ou fingir orientar os projetos: eu queria manter o meu lugar estrangeiro ou de observador participante, os atores locais que decidiriam o que queriam e poderiam fazer a partir deles mesmos. Meus relatórios são realmente notas de visitas que contêm minhas reações subjetivas e questões que eu observava a partir dessa experiência. Eu creio que a minha presença ocasional e meu apoio permanente à distância ajudou a abrir perspectivas diferentes para os líderes de projetos e programas locais. Eu também estava trazendo experiência internacional e contatos muitas vezes úteis, não como modelos, mas como referências. 
RFSJ: Para quais projetos já realizou consultoria no Brasil?

H.V.: Estas missões foram geralmente curtas, entre três dias e uma semana no campo. Elas foram seguidas por contatos frequentes via internet.

- Ecomuseu de Itaipu, Foz do Iguaçu (PR) - de 1987 a 2010 - missão de acompanhamento da configuração do ecomuseu desde a sua criação, implantação do Programa "Cultivando Àgua Boa”, relação com o lado paraguaio (Museu da Terra Guarani).

- Ecomuseu da Santa-Cruz (Rio de Janeiro) - de 1992 a 2012 - participação nos Encontros Nacionais (Jornadas de Ecomuseologia, 2009) e Encontros Internacionais de Ecomuseus e Museus Comunitários (II e III EIEMC 2000 e 2004), mobilização dos agentes econômicos.

- Ecomuseu da Serra de Ouro Preto (MG) - 2008-20I2 - Organização do Ecomuseu, medotologia de inventário do patrimônio, integração do ecomuseu na rede de museus e sítios do patrimônio de Ouro Preto e da Bacia do Ouro, criação de um parque arqueológico.

- Ecomuseu da Amazônia, Belém (PA) - 2009-20 12 - Organização do Ecomuseu, dinâmicas de micro-desenvolvimento e de micro-economia nos diversos territórios do ecomuseu, preparação do IV EIEMC, método de inventário, aplicação de cursos de capacitação, promoção do artesanado de bases tradicionais.

- Rio Grande do Sul - 1992-20I2 - visitas quase todos os anos para consulta em diversos sítios: Rio dos Sinos, Picada Café, Quarta Colônia, Porto Alegre (Orçamento Participativo e Lomba do Pinheiro), São Miguel das Missões, Pelotas.

Intervenções diversas:

- Fundação Oswaldo Cruz - 1994 (?) - relação da Fundação com as favelas vizinhas.

- Organização e acompanhamento de uma viagem de estudos de ecomuseólogos brasileiros em alguns ecomuseus da Europa (20I I).

- Apoio à criação da Associação Brasileira de Ecomuseus e Museus Comunitários (ABREMC)

Todas estas ações foram objeto de notas e relatórios em francês, o principal foi traduzido para o português. Mas estes documentos são propriedade dos organismos que me contrataram.

Entrevistado: Hugues de Varine (H.V.)

Roteiro: Roberto Fernandes dos Santos Junior

Supervisão e tradução: Clovis Carvalho Britto

Local e data: Paris, 22 de janeiro de 2017. 